\title{
Avaliação da redução microbiana do sistema de canais radiculares após a Terapia Fotodinâmica (TFD) - estudo in vivo
}

Evaluation of microbial reduction of the root canal system after Photodynamic Therapy (PDT) - in vivo study

Evaluación de la reducción microbiana del sistema de conductos dentales después de la Terapia

Fotodinámica (TFD) - estudio in vivo

Recebido: 23/08/2021 | Revisado: 27/08/2021 | Aceito: 05/09/2021 | Publicado: 06/09/2021

\author{
Diego Portes Vieira Leite \\ ORCID: https://orcid.org/0000-0003-4936-3649 \\ Universidade Cruzeiro do Sul, Brasil \\ E-mail: odontoportescursos@gmail.com \\ André Hayato Saguchi \\ ORCID: https://orcid.org/0000-0002-1903-4986 \\ Universidade Cruzeiro do Sul, Brasil \\ E-mail: andre_saguchi@yahoo.com.br \\ Stephanie Tiemi Kian Oshiro \\ ORCID: https://orcid.org/0000-0002-3515-3715 \\ Universidade Cruzeiro do Sul, Brasil \\ E-mail: steoshiro@gmail.com \\ Igor Prokopowitsch \\ ORCID: https://orcid.org/0000-0001-5858-5249 \\ Universidade de São Paulo, Brasil \\ E-mail: igor@usp.br \\ Ricardo Scarparo Navarro \\ ORCID: https://orcid.org/0000-0003-4351-8048 \\ Universidade Brasil, Brasil \\ E-mail: ricardosnavarro@gmail.com \\ Ângela Toshie Araki Yamamoto \\ ORCID: https://orcid.org/0000-0003-4402-7531 \\ Universidade Cruzeiro do Sul, Brasil \\ E-mail: angela.araki@cruzeirodosul.edu.br
}

\begin{abstract}
Resumo
O tratamento endodôntico tem o objetivo de remover tecidos infectados e microrganismos do sistema de canal radicular (SCR). Devido à complexidade do SCR, os métodos convencionais de irrigação e tornam limitados, assim diferentes técnicas foram introduzidas a fim de potencializar a limpeza e desinfecção dos condutos radiculares. $\mathrm{O}$ objetivo deste trabalho foi comparar a redução microbiana intracanal promovida pelo tratamento endodôntico convencional e terapia fotodinâmica (TFD) com emissão de laser na entrada e no interior do sistema radicular. $\mathrm{O}$ presente estudo submeteu pacientes com necessidades de tratamento endodôntico de acordo com os critérios de inclusão. Distribuindo em grupos G1(10) seguindo o protocolo de preparo químico- cirúrgico (PQC), G2(10) com protocolo PQC+TFD com ponteiras na entrada do canal e G3(10) no protocolo PQC+TFD com ponteira no interior do canal. Foi realizado o teste Two-way ANOVA p>0,05 para comparação entre os grupos. Os resultados mostraram que houve redução microbiana, mas não houve diferença significativa. Observou-se também que houve maior homogeneidade dos dados nos grupos irradiados (G2 e G3). Conclui-se que o TDF pode ser utilizado como coadjuvante no tratamento endodôntico com o aumento do índice de sucesso do mesmo.
\end{abstract}

Palavras-chave: Terapia fotodinâmica; Infecção endodôntica; Tratamento endodôntico.

\begin{abstract}
Endodontic treatment aims to remove infected tissues and microorganisms from the root canal system (RCS). Due to the complexity of SCR, conventional irrigation methods and become limited, so different techniques were introduced in order to enhance cleaning and disinfection of them. The objective of this experiment was to compare the intracanal microbial reduction promoted by conventional endodontic treatment and photodynamic therapy (PDT) with laser emission at the entrance and inside the root system. The present study included patients according to some inclusion criteria and they were distributed in groups as described: in groups G1(10) following the chemical preparation protocol (CPP), G2(10) with CPP+PDT protocol with tips at the entrance of the canal and G3(10) in the SCP+PDT
\end{abstract}


protocol with a tip inside the canal. Two-way ANOVA test $\mathrm{p}>0.05$ was performed for comparison between groups. The results showed a microbial reduction in all groups, but there was no significant difference between them. There was greater homogeneity of data in the irradiated groups (G2 and G3) than G1. It is concluded that PDT can be used as an adjunct to endodontic treatment with an increase in its success rate.

Keywords: Photodynamic therapy; Endodontics infection; Endodontic treatment.

\section{Resumen}

El tratamiento de endodoncia tiene como objetivo eliminar los tejidos y microorganismos infectados del sistema de conductos dentales (SCD). Debido a la complejidad del SCD, los métodos de irrigación convencionales y se vuelven limitados, por lo que se introdujeron diferentes técnicas para mejorar la limpieza y desinfección de los conductos radiculares. El objetivo de este trabajo fue comparar la reducción microbiana intracanal promovida por el tratamiento endodóntico convencional y la terapia fotodinámica (TFD) con la emisión de láser en la entrada y dentro del sistema radicular. El presente estudio presentó pacientes con necesidad de tratamiento endodóntico según criterios de inclusión, y fueron distribuidos en grupos: G1 (10) siguiendo el protocolo de preparación química (PQC), G2 (10) con protocolo PQC + TFD con puntas en la entrada del canal y G3 (10) en el protocolo PQC + TFD con punta dentro del canal. Se realizó una prueba ANOVA bidireccional p> 0,05 para la comparación entre grupos. Los resultados mostraron que hubo una reducción microbiana, pero no hubo una diferencia significativa entre los grupos. También se observó que hubo mayor homogeneidad de datos en los grupos irradiados (G2 y G3). Se concluye que el TDF se puede utilizar como complemento del tratamiento de endodoncia con un aumento en su tasa de éxito.

Palabras clave: Terapia fotodinámica; Infección endodóntica; Endodoncia.

\section{Introdução}

O principal objetivo do tratamento endodôntico é erradicar ou reduzir a população microbiana intrarradicular a níveis que permitam prevenir ou promover a cura da periodontite apical (Orstavik, 1996). A sua manutenção e/ou desenvolvimento está estritamente relacionada à presença de microrganismos no interior do canal radicular, sendo a inadequada desinfecção um dos fatores responsáveis pelo insucesso do tratamento (Alves et al., 2016; Asnaashari, 2017).

O papel dos microrganismos na periodontite apical foi estabelecido há 56 anos por Kakehashi et. al (1965) e desde então tem sido amplamente estudado. Em infecções primárias, a infecção é polimicrobiana, mista, com bactérias Grampositivas e negativas e predominância de anaeróbias estritas. Em casos de retratamento com infecções persistentes ou secundárias, as Gram-positivas são as mais frequentemente encontradas. No entanto, bactérias Gram-negativas já foram isoladas de canais com insucesso endodôntico (Siqueira e Rôças, 2009). Estes microrganismos estão altamente organizados em complexas entidades conhecidas como biofilme. A organizada compartimentalização interna do biofilme permite que bactérias de diversas espécies sobrevivam, o que torna a desinfecção do sistema de canais radiculares (SCR) desafiadora (Neelakantan et al., 2017).

A limpeza e desinfecção do SCR se dá pelo preparo químico-cirúrgico (PQC) com instrumentos endodônticos e substância química auxiliar, sendo o hipoclorito de sódio $(\mathrm{NaOCl})$ e o etilenodiamino tetracético sal dissódico com tergentol a 17\% (EDTA-T 17\%) comumente utilizados. A irrigação do SCR com estas substâncias tem como objetivo dissolver tecido pulpar (vivo ou necrótico), agir sobre o biofilme, neutralizar endotoxinas e remover smear layer. No entanto, pela complexidade do SCR, os instrumentos endodônticos bem como as substâncias químicas não alcançam todas as áreas, e o biofilme não é removido em istmos, canais acessórios, túbulos dentinários, canais curvos e ramificações (Siqueira Junior et al. 2018). O emprego de outros recursos coadjuvantes faz-se necessário, como medicação intracanal (Bloome et al, 2008), irrigação passiva ultrassônica (De Castro et al., 2016), magnificação (Kim e Baek, 2006) e terapia fotodinâmica (Pourhajibagher e Bahador, 2019). A terapia fotodinâmica (TFD) requer fonte de luz emissora- laser de baixa potência, emitindo um comprimento de onda próximo ao pico de absorção de um fotossensibilizador. Na presença de oxigênio haverá produção de oxigênio singleto e radicais livres, que provocam sérios danos aos microrganismos via oxidação irreversível dos seus componentes celulares como a membrana, mitocôndria e núcleo, conferindo assim, a ação antimicrobiana, agindo assim 
desinfecção dos canais radiculares coadjuvante ao tratamento convencional (Singh et al., 2015; Masuda et al., 2018; Vendramini et al., 2020).

O objetivo deste trabalho foi comparar a redução microbiana intracanal promovida pelo tratamento endodôntico convencional e TFD com a emissão de laser na entrada e no interior do canal radicular.

\section{Metodologia}

Este presente estudo foi submetido ao Comitê de Ética em Pesquisa da Universidade Cruzeiro do Sul, aprovado sob o protocolo CE/UCS - 0000/2015.

Foram triados 57 pacientes com necessidade de tratamento endodôntico em um consultório odontológico particular, sendo 30 selecionados de acordo com os critérios de inclusão estabelecidos: dentes unirradiculares superiores ou inferiores com rizogênese completa e cavidade endodôntica exposta ao meio bucal por processo carioso ou não, diagnosticados com periodontite apical assintomática ou abscesso periapical crônico. Os pacientes foram divididos aleatoriamente em 3 grupos experimentais: $\mathrm{G} 1(\mathrm{n}=10)$ submetido ao tratamento endodôntico convencional, $\mathrm{G} 2(\mathrm{n}=10)$ realização de TFD com aplicação do laser na entrada do canal, após tratamento endodôntico convencional, e; G3(n=10) realização de TFD com aplicação do laser no interior do canal com fibra ótica, após tratamento endodôntico convencional (Tabela 1). O preparo dos dentes, as coletas e análises microbiológicas serão descritas a seguir.

Tabela 1. Distribuição dos grupos.

\begin{tabular}{ccc}
\hline & $\mathrm{N}$ & Protocolo \\
\hline G1 & 10 & PQC \\
\hline G2 & 10 & PQC + TFD com ponteira (entrada do canal) \\
\hline G3 & 10 & PQC + TFD com fibra ótica (interior do canal) \\
\hline
\end{tabular}

Fonte: Autores.

\subsection{O preparo do dente e a $1^{\text {a }}$ coleta microbiológica (coleta inicial)}

Antes de cada sessão, os pacientes fizeram uso de bochecho com solução antisséptica de digluconato de clorexidina a 0,12\% (Fórmula \& Ação Farmácia Magistral- São Paulo- SP Brasil) durante um minuto. Após anestesia local, foi realizada profilaxia do remanescente dental com pedra pomes e taça de borracha, seguindo-se do isolamento absoluto. O acesso à câmara pulpar foi refinado com brocas 1012HL e 1016HL (KG Sorenser, Brasil) e broca Endo Z (Detsply Maillefer Instruments S/A, Tulsa, Oklahoma- USA) seguido da assepsia do campo operatório (embrocamento) com algodão embebido com clorexidina a 2\%. Uma gota de solução fisiológica estéril a 0,9\% foi inserida no interior do canal seguindo-se da agitação do conteúdo pulpar necrótico com uma lima tipo K (Detsply Maillefer Instruments S/A, Tulsa Oklahoma - USA) de fino calibre durante 5 minutos. Para a coleta inicial do conteúdo dos 3 grupos utilizou-se pontas de papel absorventes estéreis \#20 durante 1 minuto, posteriormente imersos em frasco de vidro contendo caldo BHI (Brain Heart Infusion) para o meio de cultura e cultivo para o laboratório.

\subsection{Preparo químico- cirúrgico (PQC) e a $2^{\mathrm{a}}$ coleta microbiológica (coleta intermediária)}

O comprimento de trabalho foi aferido com localizador apical (Propex.pixi, Detsply Maillefer Instruments S/A, Tulsa Oklahoma - USA) e o preparo químico- cirúrgico convencional se deu com instrumentação reciprocante R25 (VDW, Munich, 
Bavarian- Alemanha ) e solução de hipoclorito de sódio a 1\% (Fórmula \&Ação Farmácia Magistral- São Paulo- SP Brasil), seguido de irrigação com 3mL de $\mathrm{NaOCl}$ 1\%, 3mL de EDTA-T 17 \% (Fórmula \&Ação Farmácia Magistral- São Paulo- SP Brasil) e mais $3 \mathrm{~mL}$ de $\mathrm{NaOCl} 1 \%$.

a) G1 - Preencheu-se com solução fisiológica estéril a $0,9 \%$ o canal radicular, seguindo-se da agitação do conteúdo com uma lima tipo K (Detsply Maillefer Instruments S/A, Tulsa Oklahoma - USA) durante 5 minutos para então ser absorvida com uma ponta de papel absorvente (Tanari, Manacapuru, Brasil) estéril durante 1 minuto. O cone de papel foi imerso em um frasco de vidro contendo caldo BHI (Brain Heart Infusion) para o meio de cultura e cultivo para o laboratório.

\section{b) $\mathrm{G} 2$ e G3}

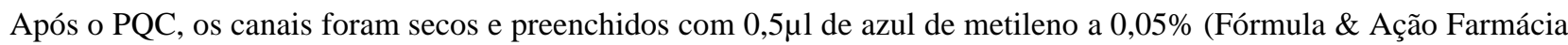
Magistral- São Paulo SP- Brasil), com o uso de uma pipeta. Após 2 minutos de tempo de pré-irradiação, foi realizada a aplicação de laser de diodo Photon III (DMC Equipamentos, Plantation- Florida- USA) de comprimento de onda de 660nm e potência de $100 \mathrm{~mW}$ durante 4 minutos. Em G2, a aplicação do laser se deu mantendo-se a ponteira na entrada do canal radicular por 1 minuto. Em G3, o laser foi aplicado utilizando-se a fibra ótica introduzida no interior do canal com movimentos helicoidais no sentido coroa-ápice a $2 \mathrm{~mm} /$ segundo, 4 vezes.

Após a irradiação, os canais de G2 e G3 foram irrigados e aspirados com $5 \mathrm{ml}$ de solução fisiológica estéril para remoção do fotosensibilizador, seguindo-se da agitação do conteúdo com uma lima tipo K (Detsply Maillefer Instruments S/A, Tulsa Oklahoma - USA) durante 5 minutos. O conteúdo intracanal foi absorvido com uma ponta de papel absorvente estéril durante 1 minuto. $\mathrm{O}$ cone de papel foi imerso em um frasco de vidro contendo caldo BHI (Brain Heart Infusion) para o meio de cultura e cultivo para o laboratório.

Após a coleta, todos os grupos foram medicados com Ultracal (Ultradent Products Inc., Utah, USA), uma bolinha de algodão estéril na entrada do canal, seguindo-se da realização de selamento duplo provisório com $1 \mathrm{~mm}$ de Coltosol (Coltène Whaledent Inc. Cuyahoga Falls-Ohio- USA) e preenchimento da cavidade pulpar com Ionômero de vidro (Ionoseal, Voco, Cuxhaven, Germany).

\section{3 - $3^{\text {a }}$ coleta microbiológica (coleta final) e obturação do canal radicular}

Após profilaxia, isolamento absoluto, remoção do selamento provisório e realização do embrocamento, realizou-se a coleta final dos 3 grupos. O canal foi preenchido com solução fisiológica estéril a $0,9 \%$ seguindo-se da agitação do conteúdo intracanal com uma lima tipo $\mathrm{K}$ durante 5 minutos. $\mathrm{O}$ conteúdo intracanal foi absorvido com uma ponta de papel absorvente estéril durante 1 minuto. O cone de papel foi imerso em um frasco de vidro contendo caldo BHI (Brain Heart Infusion) para o meio de cultura e cultivo para o laboratório.

Após a coleta final em G1, G2 e G3, o tratamento endodôntico foi finalizado.

\subsection{Avaliação microbiológica}

As análises microbiológicas das amostras dos materiais coletados foram realizadas no Laboratório de Nutrição da Universidade Federal de Pernambuco - UFPE, em capela de fluxo laminar (Veco-Campinas- São Paulo), com intuito de evitar contaminação externa das amostras.

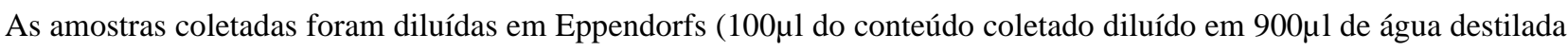
estéril). Em seguida, 100 1 dessa diluição foi aplicada em placas de Petri de 90x15mm estéril (Labware Manufaturing co Merck KGaA, Darmstadt, Alemanha), em duplicatas, contendo meio de cultura Cled Agar, KASVI (São José do Pinhais - PR). 
As placas foram colocadas na estufa incubadora à $37^{\circ} \mathrm{C}$ por 24 horas para posterior contagem das Unidades Formadoras de Colônia (UFC).

\subsection{Análise estatística}

Para análise dos dados, utilizou-se o programa IBM SPSS Statistics na versão 20.0. Os dados foram submetidos ao teste não paramétrico de Wilcoxon $(p>0,05)$ para análise intragrupos, ou seja, para a comparação dos diferentes momentos de coleta para cada tratamento instituído. Para a análise intergrupos, ou seja, comparação entre os diferentes tratamentos foi utilizada a Análise de Variância de dois fatores (Two-Way ANOVA), p>0,05.

\section{Resultados}

Os resultados da contagem do número de UFC/ml de cada coleta por grupo estão expressos nas Tabelas 1 , 2 e 3, e a média e o desvio-padrão na Tabela 4.

Tabela 2. Número de UFC/ml nas três consultas das coletas do Grupo 1 (tratamento convencional).

\begin{tabular}{c|c|c|c|c|c|c}
\hline \multirow{2}{*}{ Amostra } & \multicolumn{2}{|c|}{ Coleta 1} & \multicolumn{2}{c|}{ Coleta 2} & \multicolumn{2}{c}{ Coleta 3} \\
\cline { 2 - 7 } & $N^{\circ} \mathrm{UFC} / \mathrm{ml}$ & $\begin{array}{c}\text { Log de } \\
\text { UFC/ml }\end{array}$ & $\mathrm{N}^{\text {o UFC } / \mathrm{ml}}$ & $\begin{array}{c}\text { Log de } \\
\text { UFC/ml }\end{array}$ & $\mathrm{N}^{\text {o UFC/ml }}$ & Log de UFC/ml \\
\hline 1 & $5,28 \times 10^{2}$ & 2,72 & $1,60 \times 10^{1}$ & 1,20 & $0,00 \times 10^{0}$ & 0,00 \\
3 & $2,82 \times 10^{3}$ & 3,45 & $5,92 \times 10^{2}$ & 2,77 & $2,56 \times 10^{3}$ & 3,41 \\
4 & $4,64 \times 10^{3}$ & 3,67 & $3,20 \times 10^{1}$ & 1,51 & $2,99 \times 10^{3}$ & 3,48 \\
5 & $1,10 \times 10^{3}$ & 3,04 & $9,60 \times 10^{1}$ & 1,98 & $8,00 \times 10^{1}$ & 1,90 \\
6 & $5,92 \times 10^{2}$ & 2,77 & $2,24 \times 10^{2}$ & 2,35 & $4,61 \times 10^{3}$ & 3,66 \\
7 & $9,08 \times 10^{2}$ & 2,78 & $4,80 \times 10^{1}$ & 1,68 & $4,48 \times 10^{2}$ & 2,65 \\
8 & $3,07 \times 10^{3}$ & 3,49 & $1,76 \times 10^{2}$ & 2,25 & $0,00 \times 10^{0}$ & 0,00 \\
9 & $1,09 \times 10^{3}$ & 3,04 & $0,00 \times 10^{0}$ & 0,00 & $2,56 \times 10^{2}$ & 2,41 \\
10 & $4,80 \times 10^{1}$ & 1,68 & $8,00 \times 10^{1}$ & 1,90 & $0,00 \times 10^{0}$ & 0,00 \\
\hline
\end{tabular}

Fonte: Autores. 
Research, Society and Development, v. 10, n. 11, e463101119708, 2021

(CC BY 4.0) | ISSN 2525-3409 | DOI: http://dx.doi.org/10.33448/rsd-v10i11.19708

Tabela 3. Número de UFC/ml nas três consultas do Grupo 2 (Laser na entrada do canal).

\begin{tabular}{c|c|c|c|c|c|c}
\hline \multirow{2}{*}{ Amostra } & \multicolumn{2}{|c|}{ Coleta 1} & \multicolumn{2}{c|}{ Coleta 2} & \multicolumn{2}{c}{ Coleta 3} \\
\cline { 2 - 7 } & $\mathrm{N}^{\mathrm{o}} \mathrm{UFC} / \mathrm{ml}$ & $\begin{array}{c}\text { Log de } \\
\mathrm{UFC} / \mathrm{ml}\end{array}$ & $\mathrm{N}^{\mathrm{o}} \mathrm{UFC} / \mathrm{ml}$ & $\begin{array}{c}\text { Log de } \\
\text { UFC/ml }\end{array}$ & $\mathrm{N}^{\mathrm{o}} \mathrm{UFC} / \mathrm{ml}$ & Log de UFC/ml \\
\hline 1 & $1,60 \times 10^{1}$ & 1,20 & $1,60 \times 10^{1}$ & 1,20 & $3,20 \times 10^{1}$ & 1,51 \\
2 & $9,14 \times 10^{3}$ & 3,96 & $8,00 \times 10^{1}$ & 1,90 & $1,44 \times 10^{2}$ & 2,16 \\
3 & $1,55 \times 10^{3}$ & 3,19 & $9,60 \times 10^{1}$ & 1,98 & $2,16 \times 10^{3}$ & 3,33 \\
4 & $1,61 \times 10^{4}$ & 4,21 & $9,28 \times 10^{2}$ & 2,97 & $1,81 \times 10^{3}$ & 3,26 \\
5 & $3,68 \times 10^{2}$ & 2,57 & $1,12 \times 10^{2}$ & 2,05 & $5,12 \times 10^{2}$ & 2,71 \\
7 & $5,60 \times 10^{2}$ & 2,75 & $1,60 \times 10^{1}$ & 1,20 & $3,20 \times 10^{1}$ & 1,51 \\
8 & $2,88 \times 10^{3}$ & 3,46 & $8,00 \times 10^{1}$ & 1,90 & $2,08 \times 10^{2}$ & 2,32 \\
9 & $8,86 \times 10^{3}$ & 3,95 & $9,28 \times 10^{2}$ & 2,97 & $4,00 \times 10^{2}$ & 2,60 \\
10 & $1,54 \times 10^{3}$ & 3,19 & $6,40 \times 10^{1}$ & 1,81 & $8,80 \times 10^{2}$ & 2,94 \\
\hline
\end{tabular}

Fonte: Autores.

Tabela 4. Número de UFC/ml nas três consultas do Grupo 3 (Laser com fibra intracanal).

\begin{tabular}{c|r|r|r|r|r|r}
\hline \multirow{2}{*}{ Amostra } & \multicolumn{2}{|c|}{ Coleta 1} & \multicolumn{2}{c|}{ Coleta 2} & \multicolumn{2}{c}{ Coleta 3} \\
\cline { 2 - 7 } & $\mathrm{N}^{\circ} \mathrm{UFC} / \mathrm{ml}$ & $\begin{array}{c}\text { Log de } \\
\mathrm{UFC} / \mathrm{ml}\end{array}$ & $\mathrm{N}^{\circ} \mathrm{UFC} / \mathrm{ml}$ & $\begin{array}{c}\text { Log de } \\
\text { UFC/ml }\end{array}$ & $\mathrm{N}^{\circ} \mathrm{UFC} / \mathrm{ml}$ & Log de UFC/ml \\
\hline 1 & $4,16 \times 10^{2}$ & 2,62 & $1,44 \times 10^{2}$ & 2,16 & $1,60 \times 10^{1}$ & 1,20 \\
2 & $1,15 \times 10^{3}$ & 3,06 & $9,60 \times 10^{1}$ & 1,98 & $7,68 \times 10^{2}$ & 2,89 \\
3 & $7,57 \times 10^{3}$ & 3,88 & $2,24 \times 10^{2}$ & 2,35 & $1,28 \times 10^{2}$ & 2,11 \\
4 & $6,40 \times 10^{1}$ & 1,81 & $8,00 \times 10^{1}$ & 1,90 & $1,76 \times 10^{2}$ & 2,25 \\
5 & $7,01 \times 10^{3}$ & 3,85 & $1,12 \times 10^{2}$ & 2,05 & $1,76 \times 10^{2}$ & 2,25 \\
6 & $1,25 \times 10^{3}$ & 3,10 & $3,20 \times 10^{2}$ & 2,51 & $1,60 \times 10^{1}$ & 1,20 \\
7 & $5,44 \times 10^{2}$ & 2,74 & $8,00 \times 10^{1}$ & 1,90 & $1,44 \times 10^{2}$ & 2,16 \\
8 & $3,20 \times 10^{2}$ & 2,51 & $3,20 \times 10^{1}$ & 1,51 & $6,40 \times 10^{1}$ & 1,81 \\
9 & $1,44 \times 10^{2}$ & 2,16 & $8,00 \times 10^{1}$ & 1,90 & $1,44 \times 10^{2}$ & 2,16 \\
10 & $1,76 \times 10^{2}$ & 2,25 & $2,08 \times 10^{2}$ & 2,32 & $6,40 \times 10^{1}$ & 1,81 \\
\hline
\end{tabular}

Fonte: Autores. 
Tabela 5. Média e desvio-padrão (DP) para a contagem do Log de UFC/ml nas três consultas das coletas para os quatro grupos de tratamentos.

\begin{tabular}{ccccccc}
\hline \multirow{2}{*}{ Tratamento } & \multicolumn{2}{c}{ Coleta 1 } & \multicolumn{2}{c}{ Coleta 2 } & \multicolumn{2}{c}{ Coleta 3 } \\
\cline { 2 - 7 } & Média & DP & Média & DP & Média & DP \\
\hline $\begin{array}{c}\text { G1 - NaOCl 1\% } \\
\text { G2- Ponteira na entrada do } \\
\text { canal }\end{array}$ & 3,063 & 0,645 & 1,715 & 0,760 & 2,091 & 1,542 \\
G3 - Fibra intracanal & 3,045 & 0,946 & 1,989 & 0,597 & 2,444 & 0,648 \\
\hline
\end{tabular}

Fonte: Autores.

Analisando-se os resultados do Gráfico 1, observa-se uma elevada dispersão do UFC na terceira coleta em G1 e uma maior homogeneidade dos resultados em G2.

Gráfico 1. Boxplot do logaritmo do número de UFC.

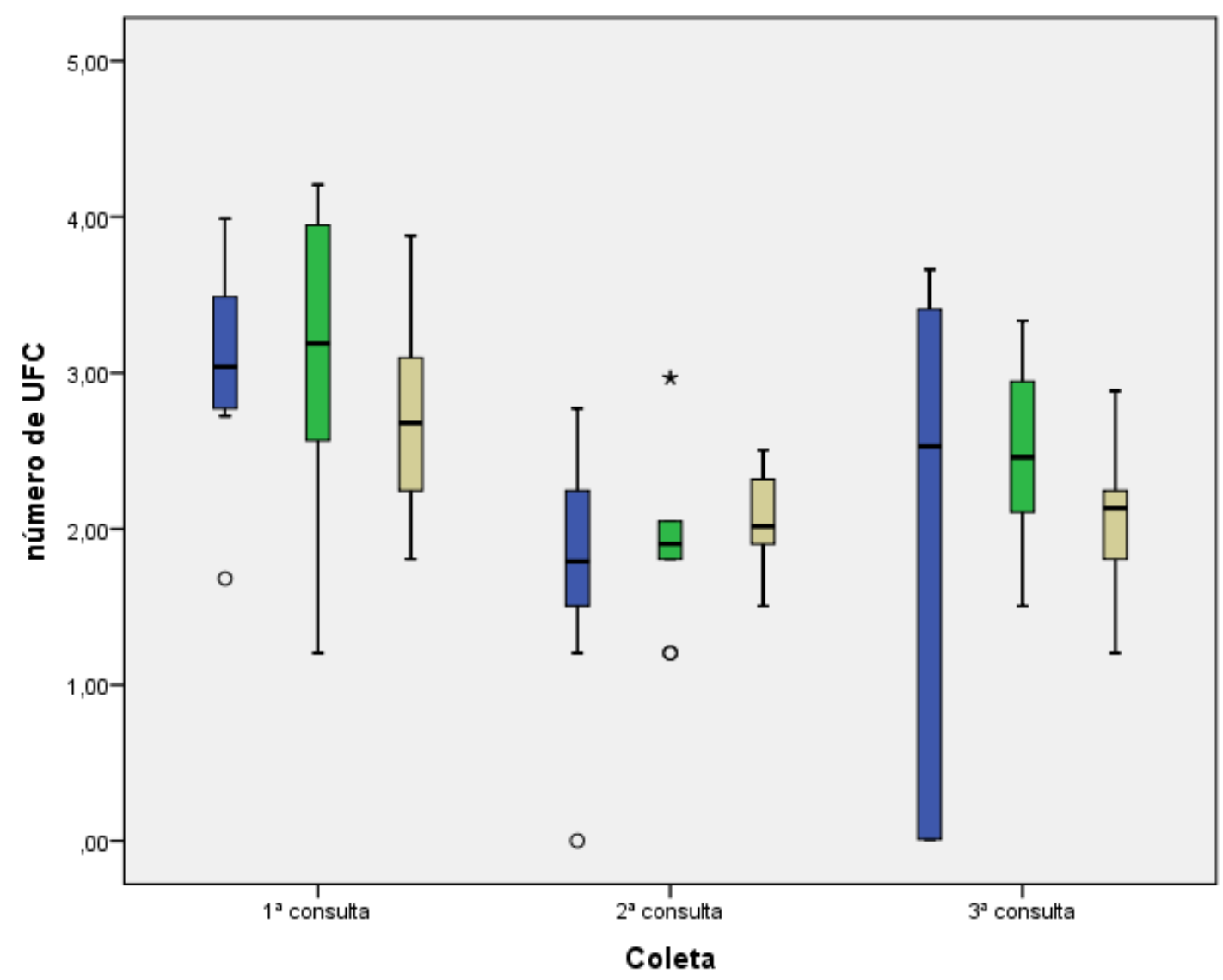

G1 tratamento sem laser

G2 - laser na entrada do canal

G3 - laser intracanal

Fonte: Autores. 
Analisando-se os dados intragrupos (Tabela 5), observa-se redução estatisticamente significativa $(\mathrm{p}<0,05)$ em: G1, entre a primeira e segunda coletas; em G2, entre a primeira e segunda, e segunda e terceira coletas; G3, entre a primeira e segunda, e primeira e terceira coletas.

Tabela 6. Resultados das comparações intragrupos considerando o número de UFC nas diferentes consultas da coleta para cada tratamento (teste de Wilcoxon pareado).

\begin{tabular}{cccc}
\hline Tratamento & Coleta & P-valor & Conclusão \\
\hline G1 & $(1 \times 2)$ & 0,007 & Diferença significativa \\
G1 & $(2 \times 3)$ & 0,074 & Não significativa \\
G1 & $(1 \times 3)$ & 0,059 & Não significativa \\
G2 & $(1 \times 2)$ & 0,008 & Diferença significativa \\
G2 & $(2 \times 3)$ & 0,037 & Diferença significativa \\
G2 & $(1 \times 3)$ & 0,093 & Não significativa \\
G3 & $(1 \times 2)$ & 0,013 & Diferença significativa \\
G3 & $(2 \times 3)$ & 0,838 & Não significativa \\
G3 & $(1 \times 3)$ & 0,013 & Diferença significativa \\
\hline
\end{tabular}

Fonte: Autores.

A comparação intergrupos realizada com a Análise de Variância de dois fatores (Two-Way ANOVA)- Tabela 6- mostra que não há diferença estatística significativa entre os tratamentos empregados $(\mathrm{p}=0,658)$.

Tabela 7. Resultados da Análise de variância.

\begin{tabular}{c|c|c|c|c|c}
\hline $\begin{array}{l}\text { Fonte de des } \\
\text { variação }\end{array}$ & $\begin{array}{l}\text { Soma } \\
\text { quadrados }\end{array}$ & $\begin{array}{l}\text { Graus de } \\
\text { liberdade }\end{array}$ & $\begin{array}{l}\text { Quadrado } \\
\text { médio }\end{array}$ & Estatística F & p-valor \\
\hline Intercepto & 166,234 & 1 & 166,234 & 486,407 & 0,000 \\
Tratamento & 0,290 & 2 & 0,145 & 0,424 & 0,659 \\
Erro & 9,227 & 27 & 0,342 & & \\
\hline
\end{tabular}

Fonte: Autores.

\section{Discussão}

A terapia fotodinâmica incide da associação de um agente fotossensibilizante, exógeno e uma fonte de luz, com o desígnio de gerar morte (necrose ou apoptose) celular, empregada em tratamento de tumores e/ou morte microbiana.

Na TFD, o mecanismo de atuação se produz quando o agente fotossensibilizante absorve os fótons da fonte de luz e seus elétrons incidem a um estado estimulado. Na presença de um substrato, como por exemplo, oxigênio, o fotosensibilizador estimulado, transfere a energia ao substrato, compondo condições reativas de oxigênio, como o oxigênio singleto, superóxidos e outros radicais livres de elevada citotoxicidade, que podem gerar sérios danos ao microrganismo ou células cancerígenas. (Dai et al. 2009) 
Para que estes estados estimulados possam acontecer, o fotosensibilizador deve absorver luz de dimensão de onda ressonante, ou seja, a banda de absorção do fotosensibilizador que precisa combinar com a banda de emissão da fonte de luz e o azul de metileno é bem absorvido pelo comprimento de onda do laser de 660nm (Poggo et al. 2011; Nagata et al. 2012).

A TFD sustenta-se na trilogia Luz-Fotosensibilizador-Oxigênio; se a luz não alcança toda extensão do canal radicular, mesmo existindo fotosensibilizador e $\mathrm{O}_{2}$, não existirá concepção de espécies reativas e, por conseguinte, morte microbiana, diminuindo deste modo o efeito da TFD.

O tratamento endodôntico convencional reduz expressivamente o número de microrganismos persistentes, no entanto (Pinheiro et al 2015; Nardello et al 2020). A TFD, desta forma, em associação com o tratamento endodôntico pode agir como procedimento coadjuvante na redução da microbiota dos canais radiculares.

Tomando-se como alicerce tais instrumentos, Fimple et al (2008), enfocam em seus resultados que o uso de fibra óptica para irradiação intracanal, preconizam que esta fibra seja amassada a cada $1 \mathrm{~mm}$ para que estas deformidades criadas na fibra possam ocasionar epalhamento de luz e alcançar a microbiota no sistema de canais radiculares. E a cinematica da fibra óptica em oscilações helicoidais, de apical para cervical e vice-versa, durante todo procedimento de irradiação, garante a distribuição da luz em todas as paredes do canal (Garcez et al. 2010).

Neste estudo, pode-se observar a diminuição microbiana, após o preparo quimico-cirurgico, bem como após a TFD. Existe uma hogeneicidade entre os resultados dos grupos irradiados em relação ao tratamento convencional (G1).

A análise estatística mostrou que não há diferença significativa entre os grupos experimetnais. Mas, houve diferença estatística entre as sessões, após o preparo quimico-cirurgico e TFD em comparação com a primeira coleta. A constituição de oxigênio singleto é expressivamente maior quando do uso da fibra. Na qual, esta consequências aos movimentos helicoidais atingidos durante a irradiação, simulando os movimentos concretizados em uma circunstância clínica, o uso da fibra óptica para irradiação intracanal, quando presumível, é seguramente aconselhado.

Outro aspecto importante a considerar, é o tempo de pré-irradiação tempo em que se consente o FS em contato com o microrganismo para que este possa adentrar ou ao menos se acoplar a membrana e acrescer os danos determinados a este.

\section{Conclusão}

Embora estudos clínicos randomizados sejam importantes na determinação da eficácia de um tratamento, por este estudo experimental pode-se concluir que a TFD com a fibra intracanal ou com a luz na entrada do canal pode ser utilizada como coadjuvante do tratamento endodôntico convencional de dentes com periodontite apical. Esta associação poderá promover o aumento no índice de sucesso do tratamento endodôntico.

\section{Agradecimentos}

Ao Professor Dr. José Fernando Cardoso Ayres cuja participação e conhecimento foram essenciais para o desenvolvimento do trabalho.

\section{Referências}

Alshanta, O. A., Shaban, S., Nile, C. J., McLean, W., \& Ramage, G. (2019). Candida albicans biofilm heterogeneity and tolerance of clinical isolates: implications for secondary endodontic infections. Antibiotics. 8(4):204. 10.3390/antibiotics8040204

Alves, F. R., Andrade-Junior, C. V., Marceliano-Alves, M. F., Perez, A. R., Rocas, I. N., Versiani, M. A., Sousa-Neto, M. D., Provenzano, J. C., \& iqueira, J. F., Jr. (2016). Adjunctive Steps for Disinfection of the Mandibular Molar Root Canal System: A Correlative Bacteriologic, Micro-Computed Tomography, and Cryopulverization Approach. J. Endod. 42(11): 1667-1672. 10.1016/j.joen.2016.08.003

Amaral, R. R., Cohen, S., Ferreira, M. V. L., Soares, B. M., \& Cortês, M. I. S. (2019). Antimicrobial Photodynamic Therapy associated with long term success in endodontic treatment with separated instruments: A case report. Photodiagnosis and Photodyn Ther. 26:15-18. 10.1016/j.pdpdt.2019.02.015 
Asnaashari, M. et al. (2017). A comparison between effect of photodynamic therapy by LED and calcium hydroxide therapy for root canal disinfection against Enterococcus faecalis: A randomized controlled trial. Photodiagnosis Photodyn Ther. 17: 226-232. 10.1016/j.pdpdt.2016.12.009

Blome, B., Braun, A., Sobarzo, V., \& Jepsen, S. (2008). Molecular identification and quantification of bacteria from endodontic infections using real-time polymerase chain reaction. Oral Microbiol Immunol. 23(5):384-390. 10.1111/j.1399-302X.2008.00440.x

Dai, T., Huang, Y. Y., \& Hamblin, M. R. (2009). Photodynamic therapy for localized infections--state of the art. Photodiagnosis Photodyn Ther. 6(3-4):170188. 10.1016/j.pdpdt.2009.10.008

De Castro, F. P., Pinheiro, S. L., Duarte, M. A., Duque, J. A., Fernandes, S. L., Anchieta, R. B., \& Bueno, C. E. S. (2016). Effect of time and ultrasonic activation on ethylenediaminetetraacetic acid on smear layer removal of the root canal. Microsc Res Tech. 79:1062-1068. 10.1002/jemt.22746

Kakehashi, S., Stanley, H., \& Fitzgerald, R. (1965). The effects of surgical exposures of dental pulps in germ-free and conventional laboratory rats. Oral Surg Oral Med Oral Pathol. 20(3):340-349. 10.1016/0030-4220(65)90166-0

Kandaswamy, D., \& Venkateshbabu, N. (2010). Root canal irrigants. J Conserv Dent. 13(4):256. 10.4103/0972-0707.73378

Kim, S., \& Baek, S. (2004) The microscope and endodontics. Dent Clin North Am. 48(1):11-18. 10.1016/j.cden.2003.12.001

Masuda, Y., Sakagami, H., Horiike, M., Kadokura, H., Yamasaki, T., \& Klokkevold, P. R. (2018). Photodynamic therapy with pyoktanin blue and diode laser for elimination of enterococcus faecalis. In Vivo. 32(4):707-712. 10.21873/invivo.11298

Nardello, L. C. L., et al. (2020). Analysis of Active Bacteria Persisting after Chemomechanical Procedures: An RNA- and DNA-based Molecular Study. J Endod. 46(11): 1570-1576. 10.1016/j.joen.2020.08.004

Orstavik, D. (2016). Time-course and risk analyses of the development and healing of chronic apical periodontitis in man. Int Endod J. 29(3):150-155. 10.1111/j.1365-2591.1996.tb01361.x

Pinheiro, E. T., Candeiro, G. T., Teixeira, S. R., Shin, R. C., Prado, L. C., Gavini, G., Mayer, M. P. (2015). RNA-based Assay Demonstrated Enterococcus faecalis Metabolic Activity after Chemomechanical Procedures. J Endod. 41(9):1441-1444. 10.1016/j.joen.2015.04.020

Plotino, G., Grande, N. M., \& Mercade, M. (2019). Photodynamic therapy in endodontics. 52(6):760-774. 10.1111/iej.13057

Pourhajibagher, M., \& Bahador, A. (2019). Adjunctive antimicrobial photodynamic therapy to conventional chemo-mechanical debridement of infected root canal systems: A systematic review and meta-analysis. Photodiagnosis Photodyn Ther. 26:19-26. 10.1016/j.pdpdt.2019.02.009

Singh, S., Nagpal, R., Manuja, N., \& Tyagi, S. P. (2015). Photodynamictherapy: an adjunctto conventional root canal disinfection strategies. Aust Endod J. 41(2): 54-71. 10.1111/aej. 12088

Siqueira, J. F. Jr, \& Rocas, I. N. (2009). Distinctive features of the microbiota associated with different forms of apical periodontitis. J Oral Microbiol. 1(1):2000-2297. 10.3402/jom.v1i0.2009

Siqueira Junior, J. F., Rôças, I. D. N., Marceliano-Alves, M. F., Pérez, A. R., \& Ricucci, D. (2018). Unprepared root canal surface areas: causes, clinical implications, and therapeutic strategies. Braz Oral Res. 32(suppl):e65. 10.1590/1807-3107bor-2018.vol32.0065

Vendramini, Y., Salles, A., Portella, F. F., Brew, M. C., Steier, L., de Figueiredo, J. A. P., \& Bavaresco, C. S. (2020). Antimicrobial effect of photodynamic therapy on intracanal biofilm: A systematic review of in vitro studies. Photodiagnosis Photodyn Ther. 32:1572-1000. 10.1016/j.pdpdt.2020.102025 